
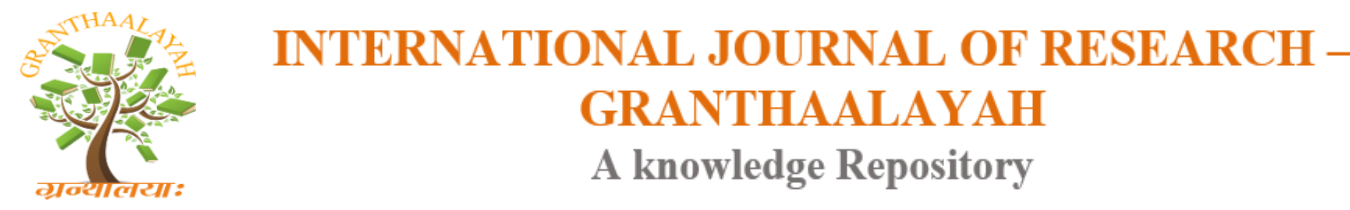

Social

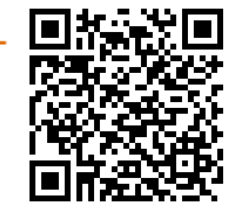

\title{
SELF ESTEEM IN RELATION TO ACADEMIC ACHIEVEMENT AMONG HIGHER SECONDARY STUDENTS
}

\author{
I. Maria Cecily ${ }^{* 1}$, Mr. S.Justin Jebaraj ${ }^{2}$ \\ ${ }^{*}$ MEd Scholar, RVS College of Education, India \\ ${ }^{2}$ M.A., M,.Phil., NET, Assistant Professor in Tamil, RVS College of Education, India
}

DOI: https://doi.org/10.29121/granthaalayah.v5.i5(SE).2017.1963

\begin{abstract}
Self - esteem is how we value ourselves; it is how we perceive our value to the world and how valuable we think we are to others. Self - esteem affects our trust in others, our relationship, our work - nearly every part of our lives. Positive self - esteem gives us the strength and flexibility to take charge of our lives and grow from our mistakes without the fear of rejection. The paper is an attempt to find to identify self-esteem in relation to academic achievement among higher secondary students. The investigator adopted the survey method to study self-esteem of higher secondary students. The study is based on primary data which is collected from 300 higher secondary students in and around Coimbatore district using simple random sampling technique. The findings reveal that totally $25.66 \%$ of the selected higher secondary students belong to low level of self-esteem, $42.33 \%$ of the selected higher secondary students belong to moderate level of self-esteem, $32 \%$ of the selected higher secondary students belong to high level of self-esteem. Totally $24.3 \%$ of the selected higher secondary students belong to low level of Academic Achievement, $28.4 \%$ of the selected higher secondary students belong to moderate level of Academic Achievement, and $47.3 \%$ of the selected higher secondary students belong to high level of Academic Achievement. Also it is found that there is no significant difference in selfesteem in relation to academic achievement among the selected higher secondary school students.
\end{abstract}

Keywords: Environmental Awareness; Education; School Students \& Promotion.

Cite This Article: I. Maria Cecily, and Mr. S.Justin Jebaraj. (2017). "SELF ESTEEM IN RELATION TO ACADEMIC ACHIEVEMENT AMONG HIGHER SECONDARY STUDENTS.” International Journal of Research - Granthaalayah, 5(5)SE, 27-32. https://doi.org/10.29121/granthaalayah.v5.i5(SE).2017.1963.

\section{Introduction}

Self-esteem can be defined as an individual's judgment of his or her self-worth (Rosenberg 1965). Self-esteem is generally considered the evaluative component of the self-concept, a 
broader representation of the self that includes cognitive and behavioral aspects as well as evaluative or affective ones (Tomaka \& Blascovich, 1991). While the construct is most often used to refer to a global sense of self-worth, narrower concepts such as self-confidence or bodyesteem are used to imply a sense of self-esteem in more specific domains. It is also widely assumed that self-esteem functions as a trait, that is, it is stable across time within individuals. Self-esteem is an extremely popular construct within psychology, and has been related to virtually every other psychological concept or domain, including personality (e.g., shyness), behavioral (e.g., task performance), cognitive (e.g., attribution bias), and clinical concepts (e.g., anxiety and depression). Environment of acceptance and success raises self-esteem, while environment of failures lower it. Studies suggest that for children of age seven to adolescents, school frequently represents the first occasion in which they act on their own and measure themselves against others. Thus school represents an initial proving ground.

The image one has about one selves as children often affects how one feel about one selves as adults. Academic challenges may lead to low self-esteem. Withdrawal and behavior problems (Kemp and Segal 1998). Adolescents with learning difficulty have trouble expressing their feelings, calming themselves down, and reading non-verbal cues which can lead to difficulty in the classroom and with their peers. Usually, as early as in Kindergarten children with learning disability are smart enough to figure out that their peers are able to recognize letters and play with symbols successfully and they are not (Stephen 2001).

Many adolescents with learning disability are teased and taunted all their lives, and they feel as rotten about themselves that, even when they succeed, they are not comfortable with themselves (Smith 2001). They are constantly looking for any situation where they could possibly fail and be made fun of. So much of their energy is consumed by fear of failure that the learning disabled often don't have much energy left to tackle the learning disability.

\section{Research Design}

The study aimed to identify the self-esteem in relation to academic achievement among higher secondary students. In the present study survey method was used. The investigator adopted the survey method to study self-esteem of higher secondary students. The study is based on primary data which is collected from 300 higher secondary students in and around Coimbatore district.

\section{HYPOTHESIS 1:}

There will be a difference in the level of self-esteem among the selected higher secondary students.

Table 1: Frequency and percentage difference in the level of self-esteem among the selected higher secondary students.

\begin{tabular}{|c|c|c|c|c|c|c|c|c|}
\hline \multicolumn{9}{|c|}{ SELF ESTEEM } \\
\hline \multicolumn{3}{|c|}{ Low } & \multicolumn{3}{|c|}{ Moderate } & \multicolumn{3}{|c|}{ High } \\
\hline Q1 & $\mathbf{F}$ & $\%$ & $\mathbf{Q 2}^{2}$ & $\mathbf{F}$ & $\%$ & Q3 & $\mathbf{F}$ & $\%$ \\
\hline 54 & 77 & $25.66 \%$ & 58 & 127 & $42.33 \%$ & 61 & 96 & $32 \%$ \\
\hline
\end{tabular}

Table 1 exhibits the result of self-esteem among the selected higher secondary students. 
According to the table totally $25.66 \%$ of higher secondary student belong to low level of self esteem, $42.33 \%$ of higher secondary students belong to moderate level of self esteem, 32\% of higher secondary students belong to high level of self esteem. So the hypothesis No: 1 is accepted. Thus it is inferred that there is a difference in the level of self esteem among the selected higher secondary students.

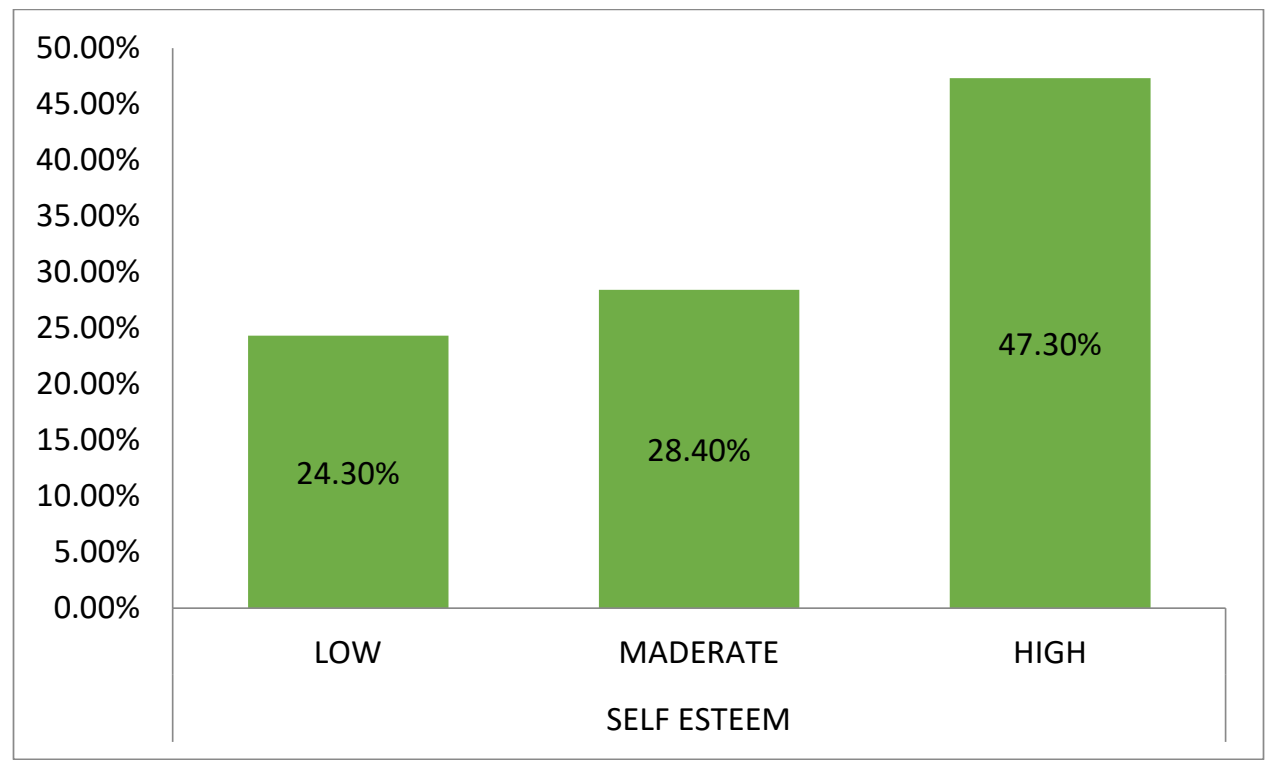

Chart 1: Difference in the Level of Self Esteem among the Selected Higher Secondary Students.

\section{HYPOTHESIS 2:}

There will be a difference in the level of academic achievement among the selected higher secondary students.

Table 2: Frequency and percentage difference in the level of academic achievement among the selected higher secondary students.

\begin{tabular}{|c|c|c|c|c|c|c|c|c|}
\hline \multicolumn{9}{|c|}{ ACADEMIC ACHIEVEMENT } \\
\hline \multicolumn{3}{|c|}{ Low } & \multicolumn{3}{|c|}{ Moderate } & \multicolumn{3}{|c|}{ High } \\
\hline Q1 & $\mathbf{F}$ & $\%$ & Q2 & $\mathbf{F}$ & $\%$ & Q3 & $\mathbf{F}$ & $\%$ \\
\hline 40 & 76 & $24.3 \%$ & 63 & 89 & $28.4 \%$ & 76 & 148 & $47.3 \%$ \\
\hline
\end{tabular}

Table 2 exhibits the result of the Academic Achievement among the selected higher secondary students. According to the table totally $24.3 \%$ of the selected higher secondary students belong to low level of Academic Achievement, $28.4 \%$ of the selected higher secondary students belong to moderate level of Academic Achievement, and $47.3 \%$ of the selected higher secondary students belong to high level of Academic Achievement. So hypothesis No: 2 is accepted. Thus it is inferred that there is a difference in the level of academic achievement among the selected higher secondary students. 


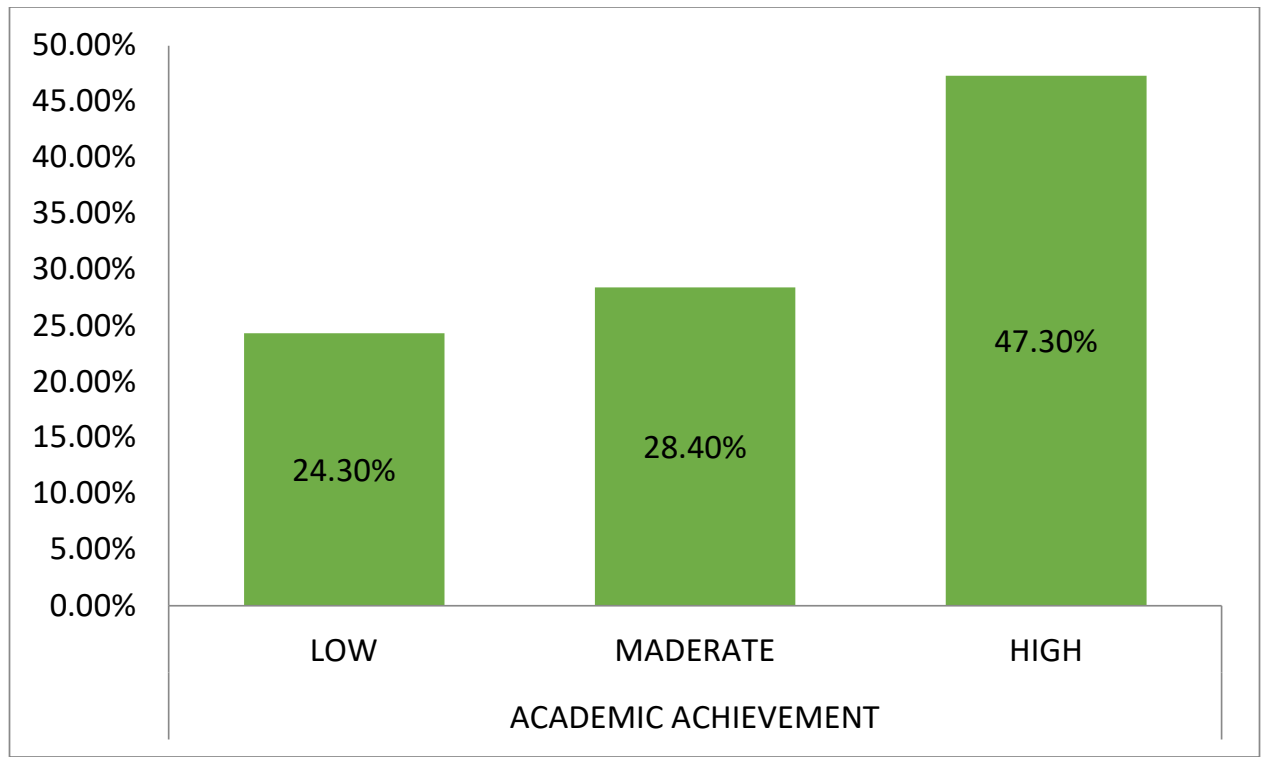

Chart 2: Difference in the Level of Academic Achievement among te Selected Higher Secondary Students

\section{HYPOTHESIS 3:}

There will be a significant relationship between self-esteem and academic achievement among the selected higher secondary students.

Table 3: Relationship between self-esteem and academic achievement among the selected higher secondary students.

\begin{tabular}{|l|l|l|l|}
\hline Variables & $\mathbf{N}$ & 'r' Value & Result \\
\hline Self Esteem & 300 & & \\
\cline { 1 - 2 } $\begin{array}{l}\text { Academic } \\
\text { achievement }\end{array}$ & 300 & .057 & N.S. \\
\hline
\end{tabular}

Table 3 exhibits the Pearson Correlation Coefficient value (0.056) which is not significant at 0.05 level. Hence the Hypothesis 3 is rejected and it is inferred that there is no significant relationship between self-esteem and academic achievement among the selected higher secondary students. 


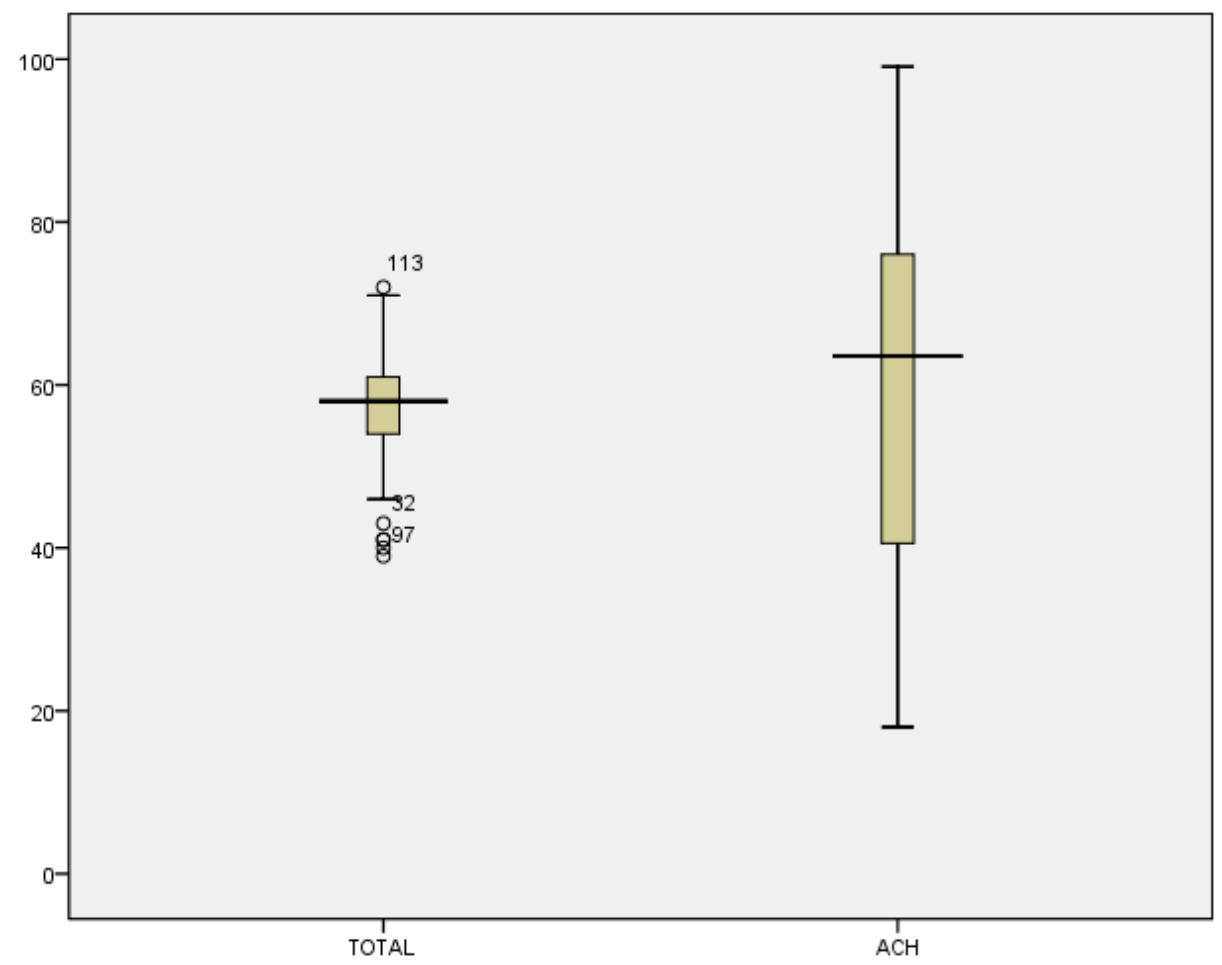

Chart 3: Relationships between Self Esteem and Academic Achievement

Chart 3 represents relationship between self-esteem and academic achievement among higher secondary school students

\section{Conclusion}

The findings reveal that totally $25.66 \%$ of the selected higher secondary students belong to low level of self-esteem, $42.33 \%$ of the selected higher secondary students belong to moderate level of self-esteem, $32 \%$ of the selected higher secondary students belong to high level of self-esteem. Totally $24.3 \%$ of the selected higher secondary students belong to low level of Academic Achievement, $28.4 \%$ of the selected higher secondary students belong to moderate level of Academic Achievement, and $47.3 \%$ of the selected higher secondary students belong to high level of Academic Achievement. Also it is found that there is no significant difference in selfesteem in relation to academic achievement among the selected higher secondary school students.

\section{References}

[1] Agaliotis, I., and Kalyva, E. (2006). Nonverbal social interaction skills of children with learning disabilities. Research in Developmental Disability, 118 -125.

[2] Blake and Slate. (1993).Internal/External Locus of Control, Self-Esteem, and Parental Verbal Interaction of At-Risk Black Male Adolescents. The journal of social psychology, 134(3), 45-48.

[3] Bryan, T. (1999). Assessing the personal and social status of students with learning disabilities. Learning Disabilities Research \& Practice, 12, 63-76. 
[4] Golden, S. A. R. (2011). Problems and Prospectus of Distance Education. Quality Enhancement In Distance Education For Life Long Learning, 1(1), 343-344.

[5] Golden, S. A. R. (2016). RURAL STUDENTS' ATTITUDE TOWARDS ENGLISH AS MEDIUM OF INSTRUCTION IN HIGHER EDUCATION - AN ANALYSIS. International Journal of Research, 3(Special Issue - 16), 1-10.

[6] Golden, S. A. R. (2017). Attitude of Students and Teachers towards E- Learning - An Analysis. Recent Research in Social Science \& Humanities, 1, 5-10.

[7] Matsuo, K. (1997). "Young Children's Comprehension of Figurative Language which Describe Emotions." Japanese Journal of Developmental Psychology, 8:165-175.

[8] Nieman,P. ( 2002). Psychosocial aspects of physical activity, Paediatr Child Health, 7(5), 309312.

[9] Patil, M., Saraswathi, G., and Padakannaya, P. (2009). A study on Self-esteem and Adjustment among Children with Reading and Writing Difficulties. Study Home Communication Science, 3, 91-96. 